\title{
The effects of scopolamine on preexposure to a learning apparatus*
}

\author{
MICHAEL J. GRANT and RUTH M. GRANT \\ University of Bridgeport, Bridgeport, Conn. 06604
}

Forty-eight random-bred male mice (CFW, Carsworth Laboratory) were divided randomly into saline or scopolamine $(1.0 \mathrm{mg} / \mathrm{kg})$ treatment groups, with each of these groups being subdivided into either an exposed or a nonexposed group. The exposed group animals were given the appropriate injections (ip) $20 \mathrm{~min}$ prior to being allowed to explore both sides of a shuttlebox for $30 \mathrm{~min}$ for 10 preexposure sessions. The nonexposed group animals were injected and placed in a carrying cage for each of the 10 sessions. After these sessions, all animals were placed in the shuttlebox and given a series of signaled one-way shuttle avoidance trials. The saline exposed group required significantly fewer trials to criteria than the scopolamine exposed group. It was also found that scopolamine was capable of attenuating the normally occurring decrement in locomotor activity across exposure sessions.

Exposing an organism to a learning apparatus can be viewed as a situation in which the investigator has placed many irrelevant stimuli in competition with the one he considers relevant (the CS). The learning apparatus surrounds the organism with a novel environment. It has been demonstrated that exposure to a novel environment can elicit exploratory responses, reflected in locomotor activity, and that these responses decrease with an increase in exposure time (Grant, 1969). This decrease in responding with repeated response elicitations can be considered as habituation to the stimuli present in a novel environment. In testing the effects of habituating an animal to a learning apparatus, Grant \& Young (1971) preexposed mice to a shuttlebox until exploratory activity had reached a baseline. When preexposed animals were compared with nonexposed controls, they demonstrated significantly more rapid acquisition of a signaled one-way shuttle avoidance response. Conversely, if animals are habituated to the CS prior to the onset of conditioning trials, a disruption of subsequent conditioning has been observed (Carlton \& Vogel, 1967; Lubow, 1965).

Carlton $(1965,1966)$ has argued that a relationship exists between cholinergic activity in the central nervous system and the process of habituation. His research has indicated that those drugs which block the transfer of acetylcholine (e.g., atropine, scopolamine) are capable of producing a decrement in the rate of habituation. Grant (1969) found that animals given ip injections of scopolamine $(1.0 \mathrm{mg} / \mathrm{kg})$ did not display the reduction

*This paper is sponsored by William Calhoun, who takes full editorial responsibility for it. in exploratory activity characteristic of saline-treated controls. Leaton (1967) has reported that animals injected with scopolamine $(0.5 \mathrm{mg} / \mathrm{kg})$ can be reinforced by being allowed access to an exploration box for a greater number of exposures than saline-injected animals. Carlton (1966) demonstrated that the onset of a novel stimulus (a light) can serve as a reinforcer for leverpressing in rats. There is a decrement in the rate of responding over time, indicating that the initial reinforcing effect of the stimulus is being lost. Injections of scopolamine $(0.3 \mathrm{mg} / \mathrm{kg})$ were capable of reversing this decrement.

In the present study, two variables were investigated: (1) the effect of habituating exploratory responses to a learning apparatus on subsequent learning in that apparatus and (2) the effect of injections of scopolamine administered during the habituation trials on subsequent learning. In light of the study by Grant \& Young (1971), a facilitation of acquisition as a function of preexposure was hypothesized. Since this facilitation has been hypothesized as resulting from habituation to environmental stimuli and since scopolamine has been observed to disrupt this process, it was also hypothesized that those animals exposed after injections of scopolamine would demonstrate significantly slower rates of acquisition than saline-treated animals.

\section{METHOD \\ Subjects}

The Ss were 48 male mice from a random-bred strain (CFW, Carsworth Laboratory) who were approximately 50 days old at the start of the study.

\section{Procedure}

The apparatus consisted of a Lehigh Valley mouse shuttlebox which was wired to appropriate programming equipment to deliver a $1000-\mathrm{Hz}$ tone for $5 \mathrm{sec}$, followed by a pairing of tone and shock $(.8 \mathrm{~mA})$ until the animal escaped.

The animals were divided randomly into a saline or scopolamine $(1.0 \mathrm{mg} / \mathrm{kg})$ treatment group, with each of these groups being subdivided into either an exposed or a nonexposed group. The four groups were labeled saline exposed (S-E), saline nonexposed (S-NE), scopolamine exposed (Sc-E), and scopolamine nonexposed (Sc-NE). The exposed animals were given injections (ip) $20 \mathrm{~min}$ prior to being allowed to explore both sides of a shuttlebox for $30 \mathrm{~min}$, while their locomotor activity was being monitored by photocells. These animals were given 10 separate preexposure sessions, each separated by $24 \mathrm{~h}$ and each preceded by an injection. Nonexposed animals were removed from their home cages, given the appropriate injections, and placed in a carrying cage for each of the 10 sessions. After these sessions, all animals were placed in the shuttlebox and given a series of signaled one-way shuttle avoidance trials. All animals continued in the avoidance trials until they had reached a criterion of four consecutive shuttle avoidances. Those animals that did not reach criterion after 30 trials were removed from the box, and a score of 30 was entered for them. No drugs were 


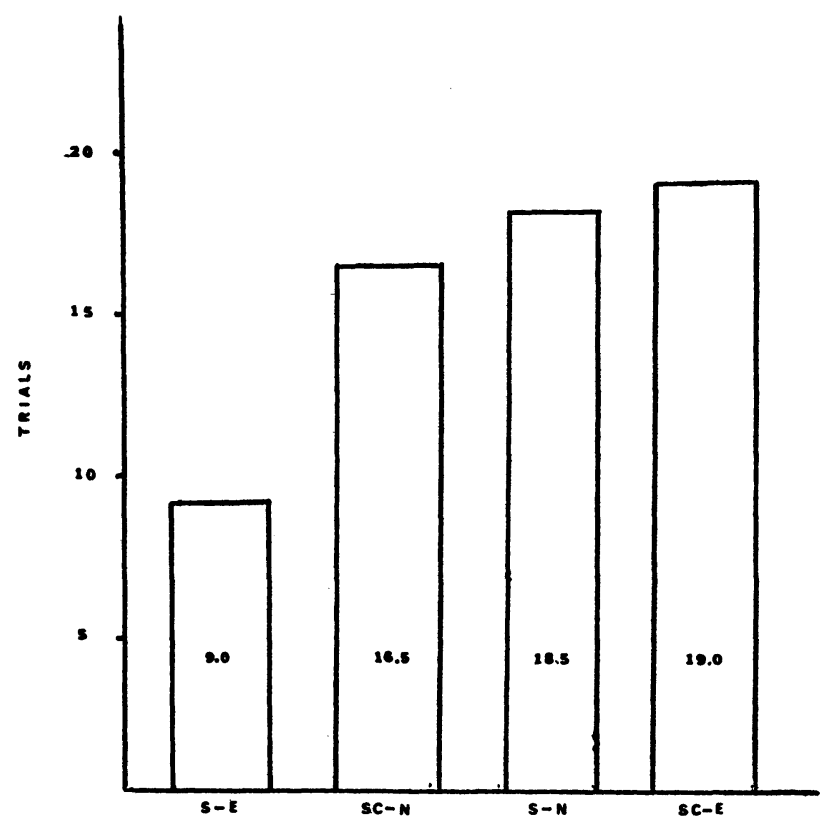

TREATMENT GROUP

Fig. 1. Median $(\mathrm{N}=12)$ locomotor activity scores as a function of number of exposure sessions.

administered during the shuttle avoidance trials. The exposure and acquisition periods were separated by $24 \mathrm{~h}$.

\section{RESULTS}

Median activity scores for the S-E and Sc-E groups over the 10 exposure sessions are presented in Fig. 1. The salient feature of these curves is the slope, or the rate of activity decrement. This is taken as an indicant of the habituation of exploratory responses and the effect of scopolamine on this process. In order to test whether there were any significant differences in this rate, activity decrement scores were computed by subtracting each animal's activity scores during Session 10 from his scores during the first session. A Mann-Whitney $U$ comparison was performed on these data, with the saline-treated animals being found to have significantly greater rates of activity decrement $(p<.05$, one-tailed). These data were collected only from those animals exposed to the shuttle apparatus (S-E and Sc-E).

In Fig. 2, the median number of trials to the learning criterion are presented for each of the four treatment groups. Mann-Whitney $U$ comparisons were computed between the S-E and S-NE groups to determine the effect of preexposure to the learning environment on subsequent learning in that environment. The results of that analysis indicated that preexposure led to a significant decrease $(p<.05$, one-tailed) in the number of trials needed to reach criterion. The same statistical analysis was applied to the Sc-E and S-E groups to evaluate the influence of scopolamine injections during the preexposure period on the acquisition of the shuttle avoidance behavior. The Sc-E Ss were found to have taken significantly more trials $(\mathrm{p}<.05)$ to reach criterion than the S-E group. Additional Mann-Whitney $\mathrm{U}$ comparisons between the Sc-NE and S-NE, the Sc-E and Sc-NE, and the S-E and Sc-NE groups did not reveal any significant differences.

\section{DISCUSSION}

The present study is in accord with the previous findings of Grant \& Young (1971) indicating that preexposure to a learning apparatus can facilitate subsequent learning in that apparatus. Introduction to a novel environment, in this case the shuttle apparatus, elicits exploratory responses which are reflected in increased amounts of locomotor activity. Normally this activity decreases over the course of repeated exposure sessions (Grant, 1969), but injections of scopolamine prior to the onset of the exposure session were capable of attenuating this decrement.

Habituation to environmental stimuli, as reflected in the decrement in activity levels over sessions, enhances the acquisition of an avoidance response in the shuttle apparatus. Those animals displaying the highest activity decrement scores were among the most rapid in reaching the learning criterion. Conversely, there were two animals in the S-E group that did not display the amount of activity decrement typical of the other animals in the group. Although these animals were included in the overall statistical analysis, an individual analysis of their performance revealed that they ranked tenth and twelfth, respectively, in the number of trials needed to reach the learning criterion. A possible reason for the facilitation of acquisition through habituation to environmental stimuli may be that, when the impact of the CS is intensified, the CS is then the one novel stimulus in the learning environment and, due to its novelty, elicits an orienting response from the organism. This leads to a more rapid acquisition of the relationship between the CS and the reinforcing stimulus. Those drugs which have been shown to disrupt the habituation process (e.g., scopolamine) help to maintain the novelty of the environmental stimuli and thus weaken the impact of the CS. It is in this manner that scopolamine disrupts the enhancement of acquisition through preexposure to the learning environment.

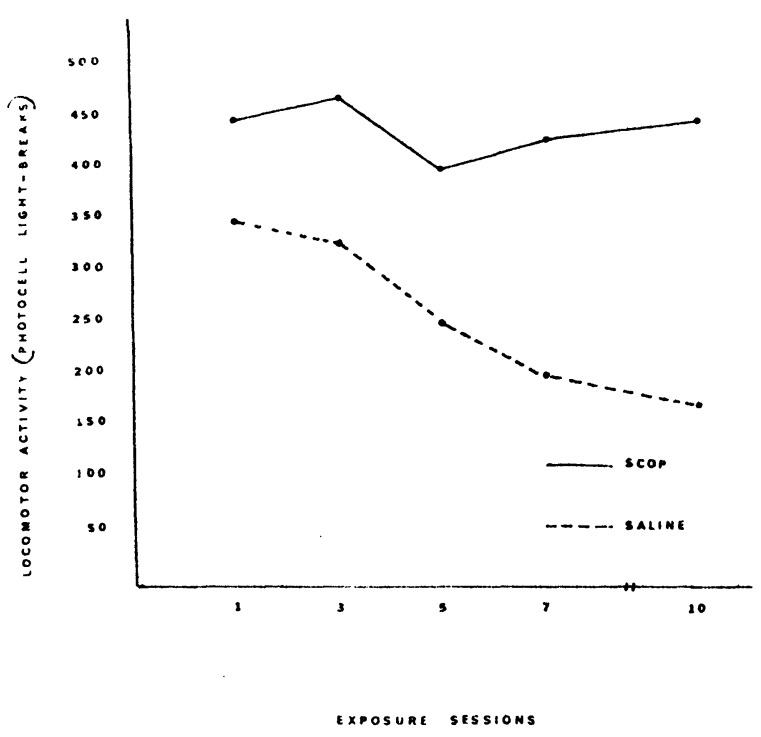

Fig. 2. Trials to shuttle avoidance criterion for each of the treatment groups. 


\section{REFERENCES}

Carlton, P. L. The hippocampus, brain acetylcholine and habituation. Paper presented at the Symposium on Brain, Biochemistry, and Behavior, American Association for the Advancement of Science, 1965.

Carlton, P. L. Scopolamine, amphetamine, and light-reinforced responding. Psychonomic Science, 1966, 5, 347-348.

Carlton, P. L., \& Vogel, J. R. Habituation and conditioning. Journal of Comparative \& Physiological Psychology, 1967, 63, 348-351.

Grant, M. Cholinergic influences on activity in a novel environment. Paper presented at meeting of the Eastern Psychological Association, 1969.
Grant, M., \& Young, D. A. The effects of preexposure to a learning apparatus. Psychonomic Science, 1971, 3, 251-252.

Leaton, $R$. N. The effects of scopolamine on exploratory motivated behavior in the rat. Paper presented at meeting of the Eastern Psychological Association, 1967.

Lubow, R. E. Latent inhibition: The effect of frequency of nonreinforced preexposure to the conditioned stimulus. Journal of Comparative \& Physiological Psychology, 1965, 60 454-457.

(Received for publication January 8, 1973.) 